\title{
Reduced expression of a gene proliferation signature is associated with enhanced malignancy in colon cancer
}

\author{
A Anjomshoaa', Y-H Lin', MA Black', JL McCall², B Humar', S Song', R Fukuzawa', H-S Yoon ${ }^{3}$, B Holzmann ${ }^{4}$, \\ J Friederichs ${ }^{4}$, A van Rij ${ }^{5}, M$ Thompson-Fawcett ${ }^{5}$ and AE Reeve ${ }^{*, 1}$ \\ 'Department of Biochemistry and Cancer Genetics Laboratory, University of Otago, Dunedin, New Zealand; ${ }^{2}$ Department of Surgery, University of \\ Auckland, Auckland, New Zealand; ${ }^{3}$ Department of Pathology, University of Otago, Dunedin, New Zealand; ${ }^{4}$ Department of Surgery, Technische \\ Universität München, München, Germany; ${ }^{5}$ Department of Medical and Surgical Sciences, University of Otago, Dunedin, New Zealand
}

The association between cell proliferation and the malignant potential of colon cancer is not well understood. Here, we evaluated this association using a colon-specific gene proliferation signature (GPS). The GPS was derived by combining gene expression data obtained from the analysis of a cancer cell line model and a published colon crypt profile. The GPS was overexpressed in both actively cycling cells in vitro and the proliferate compartment of colon crypts. K-means clustering was used to independantly stratify two cohorts of colon tumours into two groups with high and low GPS expression. Notably, we observed a significant association between reduced GPS expression and an increased likelihood of recurrence $(P<0.05)$, leading to shorter disease-free survival in both cohorts. This finding was not a result of methodological bias as we verified the well-established association between breast cancer malignancy and increased proliferation, by applying our GPS to public breast cancer data. In this study, we show that reduced proliferation is a biological feature characterizing the majority of aggressive colon cancers. This contrasts with many other carcinomas such as breast cancer. Investigating the reasons underlying this unusual observation may provide important insight into the biology of colon cancer progression and putative novel therapy options.

British Journal of Cancer (2008) 99, 966-973. doi:I 0. I038/sj.bjc.6604560 www.bjcancer.com

Published online 26 August 2008

(c) 2008 Cancer Research UK

Keywords: proliferation signature; colon cancer, disease-free survival

Defective regulation of cell proliferation is a fundamental feature of cancer. By providing a genome-wide insight, microarray technology has revealed that conserved tumour expression patterns include many proliferation-associated genes termed as 'proliferation signatures'. In most cancers, an increased expression of proliferation signatures has been associated with enhanced malignancy (Rosenwald et al, 2003; Krasnoselsky et al, 2004; Dai et al, 2005) suggesting cell proliferation as a driving force for cancer progression. Breast cancer is a typical example where the hyper-proliferative nature of more aggressive subtypes has been confirmed by array-based proliferation assays (Sorlie et al, 2001; Dai et al, 2005). These studies have also proved the superiority of cell proliferation analysis by microarrays over conventional methods regarding its objectivity and because of the assessment of multiple genes (Paik et al, 2004; Glinsky et al, 2005; Whitfield et al, 2006).

In colorectal cancer (CRC), the impact of tumour proliferation rate on malignancy is unclear because the conventional proliferation markers have produced conflicting results (Supplementary Figure 1). To date, no proliferation signature has been established to address such an association.

To investigate the association between proliferation and aggressiveness of colon cancer, we designed a colon-specific gene

*Correspondence: Professor AE Reeve;

E-mail: anthony.reeve@stonebow.otago.ac.nz

Received 3 April 2008; accepted I4 July 2008; published online 26 August 2008 proliferation signature (GPS) that was derived from common expression patterns of an in vitro CRC model, and of human colon crypt compartments as published by Kosinski et al (2007). The GPS was applied to evaluate two independant cohorts of colonic tumours and revealed an inverse relationship between tumour cell proliferation and unfavourable clinico-pathological parameters.

\section{MATERIALS AND METHODS}

\section{Cell cultures}

The following 10 CRC cell lines were used: DLD-1, HCT-8, HCT116, HT-29, LoVo, Ls174T, SK-CO-1, SW48, SW480 and SW620 (ATCC, Manassas, VA, USA). Cells were cultivated in $\alpha$-MEM supplemented with $10 \%$ foetal bovine serum, $100 \mathrm{IU} \mathrm{ml}^{-1}$ penicillin and $100 \mu \mathrm{g} \mathrm{ml}^{-1}$ streptomycin (GIBCO-invitrogen, CA, USA). Two cell cultures were established for each cell line for RNA preparation. The first culture was harvested at semi-confluence $(50-60 \%)$ when cells were actively cycling. Cells in the second culture were harvested $48 \mathrm{~h}$ after reaching full confluence, when cells were slow-growing. A replicate experiment was performed to obtain RNA for dye-reversed hybridisations.

\section{Patients}

Tumours from two cohorts of colon cancer patients were analysed. Patient follow-up was a minimum of 5 years. Disease-free survival 
(DFS) was calculated from surgery to the date of distant disease recurrence. Patients with rectal cancer, patients for whom the date of recurrence was unknown or received pre-operation adjuvant therapy were not included in this study.

Cohort A consisted of 108 New Zealand patients, who underwent surgery at Dunedin and Auckland hospitals between 1995 and 2000, and included all disease stages. Thirty patients received 5-FU-based post-operative adjuvant chemotherapy. Ethical approval was obtained from the Ethics Committee, Otago University.

Cohort B consisted of a group of 37 stage II German patients, who underwent surgery at the Technical University of Munich between 1995 and 2001. None of the patients received adjuvant therapy. Clinico-pathologic variables of both cohorts are summarised in Table 1.

\section{Array preparation and gene expression analysis}

Cohort A tumours and cell lines Gene expression profiling of cohort A tumours and cell lines was performed using arrays spotted with the MWG $30 \mathrm{~K}$ Oligo Set (MWG Biotech, NC, USA). RNA was extracted from cell lines and fresh-frozen tissues, using Tri-Reagent (Progenz, Auckland, NZ) and purified using RNeasy mini columns (Qiagen, Victoria, Australia). Ten micrograms of total RNA were oligo-dT primed and cDNA synthesis was carried out in the presence of aa-dUTP and Superscript II RNase HReverse Transcriptase (Invitrogen, CA, USA). Cy dyes were incorporated into cDNA using the indirect amino-allyl cDNA labelling method. A pooled RNA sample derived from a mixture of 12 cell lines was used as a reference for all hybridisations.

The Cy5-dUTP-tagged cDNA from an individual colorectal cell line or tissue sample was combined with Cy3-dUTP-tagged cDNA from the reference sample. The mixture was then purified using a QiaQuick PCR purification kit and co-hybridised to a microarray. Duplicate hybridisations for cell lines were performed following dye reversal.

After scanning with a GenePix 4000B microarray scanner (Axon, CA, USA), the foreground intensities from each channel were $\log _{2}$-transformed and normalised using the SNOMAD software (Colantuoni et al, 2002). Normalised values were collated and filtered using BRB-Array Tools version 3.6.0- $\beta \_3$ (by Dr Richard Simon and Amy Peng Lam, National Cancer Institute). Genes of low signal intensity, or for which more than $20 \%$ of measurements across tissue samples or cell lines were missing, were excluded from further analysis.

Cohort B tumours Total RNA was prepared from each tumour using the RNeasy mini kit (Qiagen, Hilden, Germany). Ten micrograms of total RNA were used to synthesise double-stranded cDNA with SuperScript II reverse transcriptase (Gibco-Invitrogen, NY, USA) and an oligo-dT-T7 primer (Eurogentec, Koeln, Germany). The biotinylated cRNA was synthesised from the double-stranded cDNA using the Promega RiboMax T7-kit (Promega, Madison, WI, USA) and Biotin-NTP labelling mix (Loxo, Dossenheim, Germany). The biotinylated cRNA was then purified and fragmented. The fragmented cRNA was hybridised to Affymetrix HGU133A GeneChips (Affymetrix, Santa Clara, CA, USA) and stained with streptavidin-phycoerythrin. The arrays were scanned with an HP-argon laser confocal microscope and the digitised image data were processed using the Affymetrix ${ }^{\circledR}$ microarray suite 5.0 software. Background correction and normalisation were performed in the $\mathrm{R}$ computing environment (Ihaka and Gentleman, 1996) using the robust multi-array average algorithm.

\section{Quantitative real-time PCR}

The expression of seven randomly selected genes from the GPS (MAD2L1, POLE2, CDC2, MCM6, MCM3, TOPK and GMNN) was
Table I Clinico-pathologic characteristics of two cohorts of colon cancer patients and associations with the GPS

\begin{tabular}{|c|c|c|c|c|}
\hline \multirow[b]{2}{*}{ Parameters } & \multicolumn{2}{|c|}{ Numbers } & \multirow{2}{*}{$\begin{array}{l}\text { Cohort A } \\
(P \text {-value })^{a}\end{array}$} & \multirow{2}{*}{$\begin{array}{l}\text { Cohort B } \\
\text { (P-value) }\end{array}$} \\
\hline & Cohort A & Cohort B & & \\
\hline \multicolumn{5}{|l|}{$A_{g e} e^{2}$} \\
\hline$<$ Mean & 49 & 20 & 0.33 & 0.79 \\
\hline$>$ Mean & 59 & 17 & & \\
\hline \multicolumn{5}{|l|}{ Sex } \\
\hline Male & 62 & 21 & 0.56 & 0.74 \\
\hline Female & 46 & 16 & & \\
\hline \multicolumn{5}{|l|}{ Differentiation } \\
\hline Well/moderate & 83 & 22 & 0.17 & 0.20 \\
\hline Poor & 25 & 15 & & \\
\hline \multicolumn{5}{|l|}{ Disease stage } \\
\hline 1 & 12 & 0 & 0.015 & NA \\
\hline$\|$ & 64 & 37 & & \\
\hline III & 29 & 0 & & \\
\hline IV & 3 & 0 & & \\
\hline \multicolumn{5}{|l|}{ Vascular invasion } \\
\hline Yes & 9 & 1 & 0.065 & NA \\
\hline No & 99 & 36 & & \\
\hline \multicolumn{5}{|l|}{ Lymphatic invasion } \\
\hline Yes & 23 & 3 & 0.018 & 1 \\
\hline No & 85 & 34 & & \\
\hline \multicolumn{5}{|c|}{ Lymphocyte infiltration } \\
\hline Nil/mild & 53 & 9 & 0.67 & 0.48 \\
\hline Moderate & 42 & 17 & & \\
\hline Prominent & 13 & 11 & & \\
\hline \multicolumn{5}{|l|}{ Margin } \\
\hline Infiltrative & 56 & NA & 0.84 & NA \\
\hline Expansive & 52 & & & \\
\hline \multicolumn{5}{|l|}{ Chemotherapy } \\
\hline Yes & 30 & 0 & 0.08 & NA \\
\hline No & 78 & 37 & & \\
\hline \multicolumn{5}{|c|}{ Recurrence at 5 years } \\
\hline Yes & 24 & 16 & 0.021 & 0.005 \\
\hline No & 84 & 21 & & \\
\hline Total & 108 & 37 & & \\
\hline
\end{tabular}

Abbreviations: GPS = gene proliferation signature; $N A=$ not applicable. aA Fisher's Exact test or Kruskal-Wallis test were used for testing association between clinico-pathologic parameters and the dichotomous GPS variable. ${ }^{b}$ Average age 68 and 63 years for cohort A and B patients, respectively. Bold numbers represent significant $P$-values.

validated by quantitative real-time PCR ( $\mathrm{qRT}-\mathrm{PCR}$ ) on an ABI Prism 7900HT Sequence Detection System using cell line cDNA and Taqman Gene Expression assays (Applied Biosystems, CA, USA). Relative fold changes were calculated using the $2^{-\Delta \Delta C T}$ method (Livak and Schmittgen, 2001) with Topoisomerase 3A as the internal control. Reference RNA was used as the calibrator to enable comparison between different experiments.

\section{Immunohistochemical analysis}

Ki-67 immunohistochemistry was performed on 40 cohort A tumours for which paraffin blocks were available, and an additional set of 33 rectal/rectosigmoid tumours was included to increase statistical power. Antigens were retrieved on $4-\mu \mathrm{m}$ sections in boiling citrate buffer ( $\mathrm{pH}$ 6). Primary 
antibody (MIB-1, DakoCytomation, Denmark; dilution 1:50) was detected using the EnVision system (Dako EnVision) and the DAB substrate kit (Vector Laboratories, CA, USA). Five high-power fields were counted by two observers in a blinded manner. The Ki-67 proliferation index (PI) was presented for each tumour as the percentage of positively stained nuclei.

\section{Statistical analysis}

The K-means clustering method was applied to stratify clinical samples on the basis of the GPS expression level using the TIGR MeV 4.0 software (Saeed et al, 2003). Using Pearson uncentered correlation, tumours from each cohort were assigned to two clusters (i.e., K-means clustering with $K=2,1000$ iterations of clustering) with the threshold of occurrence in the same cluster set to $80 \%$. The consensus clusters each contained tumours with similar GPS expression, resulting in two patient groups differing in their GPS levels. Either Fisher's exact test or the Kruskal-Wallis test was then used to evaluate the associations between the dichotomous GPS variable and clinico-pathologic parameters. Statistical analyses were performed using SPSS 15.0.0 (SPSS Inc., Chicago, IL, USA). For Ki-67 analysis, tumours were stratified into two clusters with the mean Ki-67 value as a cutoff point.

The gene set comparison function from the BRB-Array tools software was used to analyse the GPS for differential expression among subgroups defined by the clinico-pathologic variables. The GPS was considered to have a higher-than-expected number of genes differentially expressed (DE) between the classes being compared if the Kolmogorov-Smirnov (KS) resampling $P$-value was less than 0.005 (default value). The distribution of KS statistics was obtained by 100000 iterations of the random resampling process.

Disease-free survival was plotted using the method of Kaplan and Meier, and a log-rank test was used to test for differences in survival time between defined clusters of patients according to the GPS or Ki-67 PI. A multivariate Cox proportional hazards model was developed using forward stepwise regression with predictive variables that were significant in the univariate analysis. Cox multivariate regression was not relevant for measuring the performance of the GPS in cohort B, as this population of tumours included only stage II colon cancers.

\section{RESULTS}

\section{Derivation of a GPS}

To identify a set of genes whose expression was associated with tumour cell proliferative activity, two proliferation-based systems were analysed and integrated as described below and illustrated in Figure 1.

A. Gene expression analysis of a CRC in vitro model The in vitro system involved identification of genes that were to reflect the proliferative activity of CRC cell lines. Genes DE between exponentially growing (nonconfluent) and growth-inhibited (confluent) cell lines were identified (Figure 1A-C). Firstly, DE genes between Cy5-labelled nonconfluent and confluent samples were identified by statistical analysis of microarray (two-class paired, FDR $<1 \%$; Tusher et al, 2001). Secondly, DE genes between Cy3labelled nonconfluent and confluent samples (biological replicates) were identified using the same approach. To minimise genespecific dye bias and other sources of variation, only genes that were present in both SAM-generated gene sets were selected. The gene set was further reduced to genes whose expression was consistently altered in the same direction in at least 8 out of 10 cell lines, yielding a total $881 \mathrm{DE}$ genes with known annotation (Figure 1D).
Gene ontology (GO) analysis showed that categories related to cell cycle and DNA metabolism were the most over-represented biological themes among the $\mathrm{DE}$ genes, mainly because of genes that were overexpressed in exponentially growing cells $\left(P<10^{-5}\right)$.

B. Gene expression profile of the proliferative compartment of colon crypts The second gene set used for the design of a GPS was based on the physiological expression profile of human colon crypts. Kosinski et al (2007) compared the proliferative bottom part of crypts with the differentiated crypt top, and identified 299 DE genes highly expressed in the proliferative bottom (Figure 1E). The GO terms that were over-represented within this gene list were related to cell proliferation and renewal, consistent with the physiological function of the bottom crypt compartment.

C. Definition of the GPS To define a final GPS enriched in keyproliferative genes, the in vitro and in vivo-derived DE gene lists were screened for common genes (Figure 1F). Thirty-six genes were found to be overexpressed in both exponentially growing CRC cell lines and the proliferative crypt compartment. These genes were defined as GPS that included 15 cell cycle-related genes (Supplementary Figure 2).

The expression of 7 genes randomly selected from the 15 cell cycle-related genes was validated by $\mathrm{qRT}-\mathrm{PCR}$ on the cell line cDNAs. A close correlation between qRT - PCR and array data was observed (Supplementary Table 2).

\section{Classification of colon tumours according to the GPS expression level}

To investigate the association between the GPS and patient parameters, expression values of the GPS genes were first obtained from the array-generated expression profiles. Expression data were available for all 36 genes in cohort A, and 35 genes (except CDCA5) in cohort B tumours. For each cohort, tumours were split into two consensus clusters on the basis of their GPS expression using K-means clustering. Tumours with relatively high or low GPS expression were defined as having high or low proliferative activity, respectively (Figure 1G).

\section{Reduced expression of the GPS is associated with unfavourable clinico-pathologic variables}

Intriguingly, we observed an association between reduced GPS expression and an increased risk of recurrence in both cohorts (Table 1). Groups with reduced GPS expression were significantly enriched for recurrent tumours $(P=0.021$ and 0.005 for cohort $A$ and $B$, respectively). In cohort A, reduced GPS expression was also associated with higher disease stage $(P=0.015)$. Further, reduced GPS expression was significantly more frequent in cohort A tumours with lymphatic invasion compared with those without lymphatic invasion $(P=0.018)$. Gene set comparison analysis confirmed that GPS contained a higher-than-random proportion of DE genes among subgroups with clinico-pathologic parameters for which a significant association with the GPS was found in nonparametric tests (Supplementary Table 1).

\section{Reduced GPS expression is associated with shorter DFS in colon cancer}

To examine whether a difference in cell proliferation determined by the GPS may be associated with time to recurrence, DFS was plotted for low GPS and high GPS tumours (Figure 2). DFS was significantly shorter in patients with reduced GPS expression $(P=0.033$ and 0.011 for cohort A and B patients, respectively; Figure $2 \mathrm{~A}$ and $\mathrm{C}$ ). This association remained significant in cohort 
A

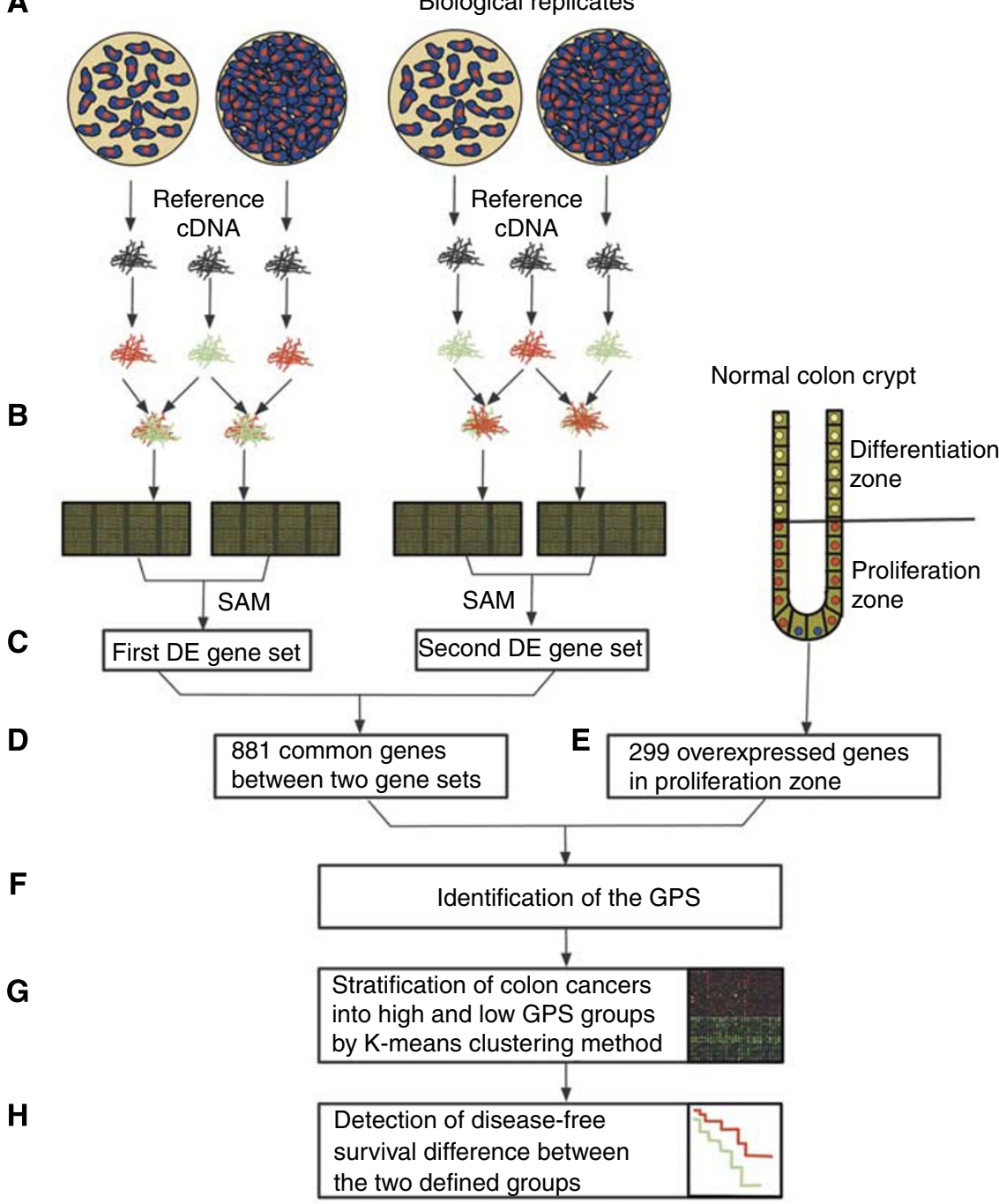

Figure I Overview methodology. A gene proliferation signature (GPS) was derived by combining the gene expression data from the analysis of a cell line model and colon crypts. (A) Ten colorectal cancer cell lines were cultured and harvested at semi-confluence and full confluence. Each cell culture was performed in duplicate. (B) Using a reference design, a mixture of sample and reference dye-labelled cDNAs was hybridised to a $30 \mathrm{~K}$ Oligo array. Dye orientation was reversed for biological replicates. (C) Statistical analysis of microarrays (SAM) was performed to identify differentially expressed (DE) genes between two stages of growth in cultures. Two gene sets were generated through the analysis of samples with identical dye labelling. (D) Only 881 genes that were presented in both SAM-generated gene sets and DE gene sets were selected. (E) Human colon crypt profiling resulted in identification of 299 DE genes with overexpression in the proliferation zone compared with the differentiation zone. (F) The GPS was generated by taking the overlapping genes between $\mathbf{D}$ and $\mathbf{E}$ gene sets. (G) Two cohorts of colon cancer patients were stratified into low and high groups according to the GPS expression using K-means clustering method. (H) Disease-free survival difference was calculated between the two defined groups.

A, when patients with adjuvant therapy were excluded $(P=0.029$; Figure 2B).

If prolifetative activity is a crucial factor influencing DFS, then a GPS consisting of only genes directly implicated in cell cycle process should be sufficient to separate patients into groups with different survival rates. Therefore, the GPS was reduced to the 15 cell cycle-regulated genes and survival analysis was repeated. The modified GPS stratified patients into groups that differed in their DFS more stringently $(P=0.022$ and 0.003 for cohort A and B patients, respectively; Figure 2D-F) than the original GPS including all 36 genes. Therefore, colon cancer patients with tumours of lower proliferative activity are more likely to recur.

When the parameters predicting patient outcome in univariate analysis were investigated in a multivariate model, disease stage was the only independant predictor of 5-year DFS in cohort A (Table 2).

\section{Increased GPS expression is associated with shorter DFS in} breast cancer

As the association between reduced GPS expression and poor colon cancer prognosis was an unexpected finding, we tested the validity of our GPS on public array data from two independant breast cancer cohorts. Using these data, an association between increased proliferation and bad outcome has been established earlier (van de Vijver et al, 2002; Pawitan et al, 2005).

For each breast cancer data set, patients were stratified into two groups with either low or high GPS expression and their DFS was plotted. In both data sets, patients with increased GPS expression had significantly shorter DFS compared with patients with reduced GPS expression $(P<0.0001$; Figure 3$)$, confirming the previously established association. Therefore, the association between low proliferation and bad colon cancer outcome is not the result of biased methodology. 

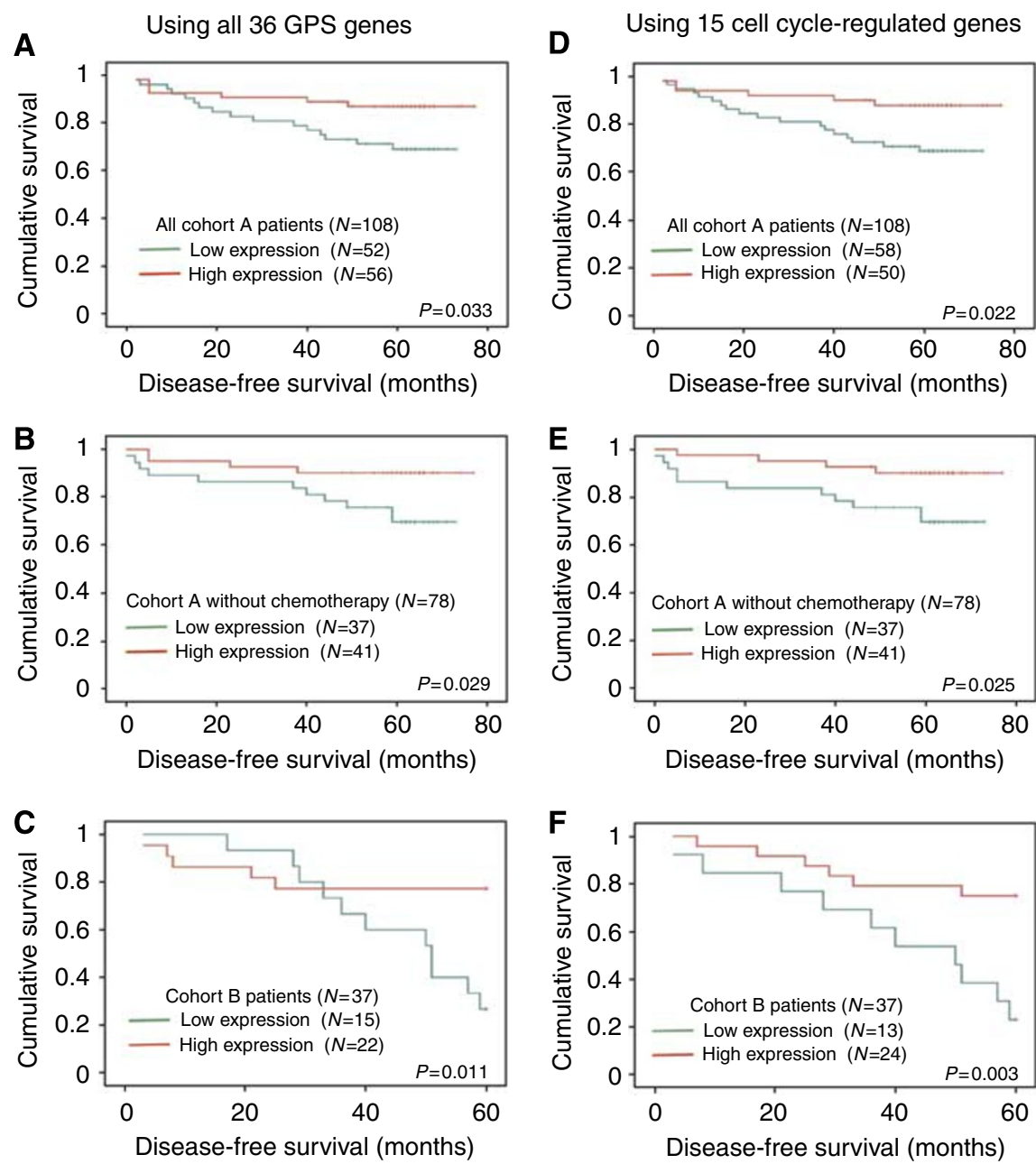

Figure 2 Disease-free survival analysis of colon cancer patients stratified into high and low groups according to the GPS expression or I5 cell cycleregulated genes included in the GPS. In both cohorts, the low GPS groups had significantly shorter DFS compared with the high GPS groups (A and C). This difference was more significant when only cell cycle-regulated genes were used to stratify patients ( $\mathbf{D}$ and $\mathbf{F})$. The same association was found when the analysis was limited to those cohort A patients who received no adjuvant therapy (B and $\mathbf{E}$ )

Table 2 Cox regression analysis of determinants of DFS in cohort A cancer patients

\begin{tabular}{lccc}
\hline & $\begin{array}{c}\text { Univariate analysis } \\
\text { Parameters }\end{array}$ & \multicolumn{2}{c}{ Multivariate analysis $^{\mathbf{a}}$} \\
\cline { 3 - 4 } & $<0.001$ & HR (Cl) & P-value \\
\hline $\begin{array}{l}\text { Disease stage } \\
(1+\| \text { vs III+IV) } \\
\text { Lymphatic invasion }\end{array}$ & $<0.001$ & - & - \\
$\begin{array}{l}(- \text { vs }+) \\
\text { Vascular invasion } \\
(- \text { vs }+)\end{array}$ & 0.012 & - & - \\
$\begin{array}{l}\text { Margin } \\
\text { (expansive vs infiltrative) }\end{array}$ & 0.015 & - & - \\
$\begin{array}{l}\text { GPS expression } \\
\text { (high vs low) }\end{array}$ & 0.022 & - & - \\
\hline
\end{tabular}

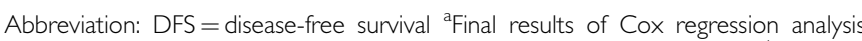
using a forward stepwise method (enter limit $=0.05$, remove limit $=0.10$ ). ' ${ }^{\text {L }}$ og-rank test $P$-value. 'Hazard ratio (HR) determined by Cox regression model; confidence interval $(\mathrm{Cl})=95 \%$.

\section{Ki-67 PI is not associated with outcome}

Ki-67 PI ranged from 25 to $96 \%$, with a mean value of $76.3 \pm 17.5$ and a median value of $81.8 \%$. When these 73 patients were stratified into two groups differing in their GPS expression, a significant difference in DFS was apparent $(P=0.01$; Supplementary Table 3). However, when patients were stratified into two groups according to the mean Ki-67 PI, the DFS of the group with a low PI was similar to that with a high PI $(P=0.55$; Supplementary Table 3). Furthermore, when analysis was limited to patients with the highest and the lowest Ki-67 values, no statistical difference in DFS was observed (data not shown). No correlation was found between the Ki-67 PI and mean GPS expression of tumours (Spearman $R=0.06 ; P=0.63$ ).

\section{DISCUSSION}

Cancer is regarded as a proliferative disorder, where a selective growth advantage is believed to crucially contribute to its development and progression. Supporting this concept are many studies that have shown an association between poor clinical outcome and high expression of proliferation-associated genes (Krasnoselsky et al, 2004; Dai et al, 2005; Kirschner-Schwabe et al, 2006).

Our study is the first to report an inverse relation between cancer malignancy and the expression of a multi-gene proliferation signature. In two independant cohorts of colon cancer patients, we observed an association between an increased recurrence risk and the reduced expression of a GPS. This finding challenges the 


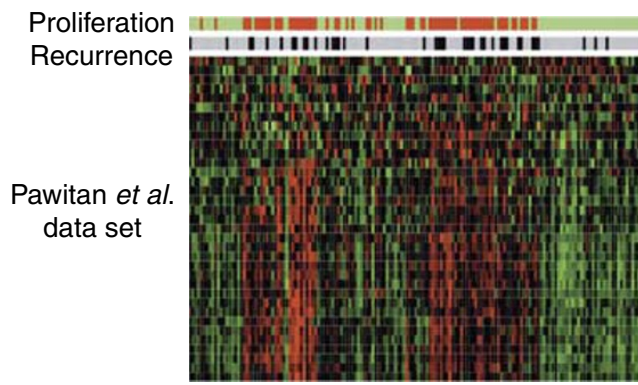

Disease-free survival (months)
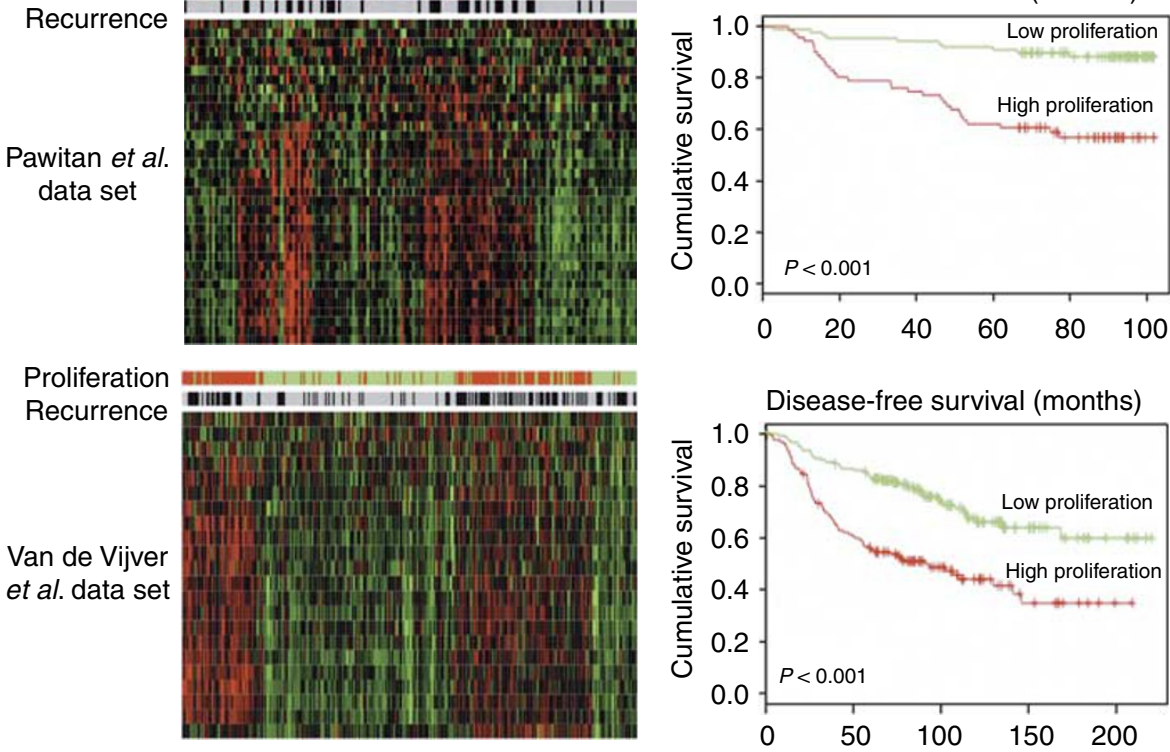

Figure 3 Stratification effect of the GPS on two cohorts of breast cancer patients. The heat maps represent the normalised gene expression values of the GPS genes across samples. Each row represents one gene and each column represents one sample. Colour bars on the top of heat maps represent proliferation groups (high proliferation is indicated in red, and low proliferation is indicated in green as defined by K-means clustering) and recurrence status (black, recurrence; grey, nonrecurrence). There is a close correlation between high GPS expression and recurrence in both cohorts. Disease-free survival is significantly shorter in the high GPS groups compared with the low GPS groups.

long-held belief that rapidly dividing cancer cells are a harbinger of poor prognosis, and suggests that low proliferative activity is a biological feature of the majority of aggressive colon cancers.

The GPS we designed is highly likely to directly reflect the proliferative state of a tumour, as it was derived from both human colon crypts and an in vitro CRC model. All genes included in the GPS were overexpressed in actively proliferating cells of the both systems. With respect to the in vitro system, the comparison of exponentially growing cancer cells with contact-inhibited cancer cells has limitations; however, well established evidence indicates that many tumour cell lines maintain a variable degree of densitydependant growth suppression that is characteristic of the stationary phase (Couldwell et al, 1992; Steinman et al, 2003; Kuhn et al, 2004; Motti et al, 2005). Ten CRC cell lines were included to ensure an overall growth suppression, and only genes were considered that were altered in at least $80 \%$ of the cell lines. By the inclusion of only DE genes that overlapped with the human colon proliferation signature, the final GPS consisted of genes that strongly correlate with both colon cancer cell growth and physiological colon proliferation. Consistent with this, ontology analysis indicated that proliferation-associated genes represent the main biological theme in both the in vitro and the in vivo system.

Further evidence supporting the association of the GPS with cell proliferation stems from a considerable overlap in genes or gene families identified between our GPS and other proliferation signatures defined for tumours of the breast (Perou et al, 1999, 2000), ovary (Welsh et al, 2001), liver (Chen et al, 2002), acute lymphoblastic leukaemia (Kirschner-Schwabe et al, 2006), neuroblastoma (Krasnoselsky et al, 2004), lung squamous cell carcinoma (Inamura et al, 2005), head and neck (Chung et al, 2004), prostate (LaTulippe et al, 2002) and stomach (Hippo et al, 2002). Comparing these published data, Whitfield et al (2006) identified a core set of genes common to various proliferation signatures. As expected, these genes (MYBL2, PLK1, CDC2 and MCM genes) are also contained within our GPS (see Supplementary Figure 2), reflecting the universal mechanisms that govern human cell division. Indeed, by reanalysis of public breast cancer data, our
GPS was shown to perform properly in other cancer types as well. Therefore, our GPS appears to be a reliable tool for the assessment of proliferation in colonic tumours.

Application of our GPS to colon cancer patient data revealed a robust association between low proliferative activity and increased likelihood of recurrence. Firstly, the low GPS group had reduced DFS in two independant cohorts derived from different populations. Secondly, expression data from the two cohorts were obtained using two different array platforms, indicating that the observed association was not subject to methodological bias. Thirdly, reduced GPS expression in cohort A also correlated with clinico-pathological variables related to poor outcome (stage, lymphatic invasion). A possible confounding factor in our study was the chemotherapy treatment as given in $28 \%$ of cohort A patients. Exclusion of these patients from analysis had no effect on the association strength, suggesting that proliferation affects patient outcome independant of adjuvant chemotherapy.

Notably, the observed association was not independant of tumour stage. In other words, higher disease stages were enriched for slowly proliferating tumours, but tumours with high GPS expression were also present. It remains possible, however, that these fast proliferating tumours had progressed slowly before they were diagnosed at an advanced stage. It is likely that tumour stage is a better prognostic factor because the presence of lymph node and distant organ involvement is a direct manifestation of metastasis. It is noteworthy that the goal of this study was not to develop a prognostic tool based on the GPS, but to determine the nature of the relationship between proliferation and the degree of malignancy in colon cancer.

Together, the analyses we performed are all consistent with a marked effect of colon cancer proliferation on the rate of its recurrence. This is an important finding because studies using conventional proliferation markers have not been able to establish a clear-cut association between colon cancer proliferation and outcome. On account of these reported inconsistencies, we also performed DFS analysis on the basis of proliferation estimated by conventional Ki-67 labelling. Unlike the GPS, Ki-67 PI failed to 
separate a set of 73 CRCs into groups associated with distinct survival (Supplementary Table 3). Although the advantage of assessing multiple genes as opposed to one proliferation marker appears obvious, additional parameters are likely to contribute to the inferior performance of the Ki-67 PI. Ki-67 positivity reflects the number of cells in cycle, rather than their cycling speed (Endl and Gerdes, 2000). Furthermore, the visual scoring of Ki-67 positive nuclei is inherently subjective, confounding correlations particularly in the case of small sample sizes (Barzanti et al, 2000). It is of interest, however, that a low Ki-67 PI has been associated with poor outcome in the three studies with the highest statistical power (i.e., largest sample sizes) (Allegra et al, 2003; Garrity et al, 2004; Hilska et al, 2005).

It is difficult to assess from our data whether slow proliferation directly enhances the ability of a colon cancer to metastasise or fast proliferation may be disadvantageous for colon cancers to acquire metastatic capacity. Although it appears intuitively logical that accelerated cell division allows for more genetic events required for progression to accumulate, fast proliferation might also have a negative impact on a tumour ability to survive and spread. For example, rapidly growing tumours may elicit a stronger and more effective immune response. Further, highly proliferative tumours may contain a lower proportion of cancer stem cells thought to undergo relatively slow divisions. Alternatively, a high level of genetic instability may increase the invasive potential of cancer cells or their resistance towards apoptosis, but may interfere with smooth replication. Also, hypoxic conditions may slow down the growth rate of tumours but could promote the onset of epithelial-mesenchymal transitions leading to invasion. Possible underlying mechanisms are currently under investigation in our laboratory.

The intriguing finding of an inverse relationship between tumour proliferative activity and disease aggressiveness suggests that fundamental biological differences exist for the mechanisms that drive disease progression in colon cancer compared with other epithelial malignancies. The delineation of the underlying processes will be important not only for the understanding of colon cancer biology, but also for the design of new therapeutic strategies. In this context, the development of alternative therapies might be a pertinent issue, given that current chemotherapeutic agents are usually designed to target colon cancer progression by killing rapidly proliferating cells.

\section{ACKNOWLEDGEMENTS}

Grant Support: Health Research Council of New Zealand, the Lottery Grants Board of New Zealand (Y-HL, AER) and the Kommission für Klinische Forschung des Klinikums rechts der Isar (JF, RR, JRS, BH, JM).

\section{Financial Disclosures}

Yu-Hsin Lin, Michael A Black are consultants and Anthony E Reeve is a director of Pacific Edge Biotechnology Ltd.

Supplementary Information accompanies the paper on British Journal of Cancer website (http://www.nature.com/bjc)

\section{REFERENCES}

Allegra CJ, Paik S, Colangelo LH, Parr AL, Kirsch I, Kim G, Klein P, Johnston PG, Wolmark N, Wieand HS (2003) Prognostic value of thymidylate synthase, Ki-67, and p53 in patients with dukes' B and C colon cancer: a National Cancer Institute-national surgical adjuvant breast and bowel project collaborative study. J Clin Oncol 21: 241-250

Barzanti F, Dal Susino M, Volpi A, Amadori D, Riccobon A, Scarpi E, Medri L, Bernardi L, Naldi S, Aldi M, Gaudio M, Zoli W (2000) Comparison between different cell kinetic variables in human breast cancer. Cell Prolif 33: 75-89

Chen X, Cheung ST, So S, Fan ST, Barry C, Higgins J, Lai K-M, Ji J, Dudoit S, Ng IOL, van de Rijn M, Botstein D, Brown PO (2002) Gene expression patterns in human liver cancers. Mol Biol Cell 13: 1929-1939

Chung CH, Parker JS, Karaca G, Wu J, Funkhouser WK, Moore D, Butterfoss D, Xiang D, Zanation A, Yin X (2004) Molecular classification of head and neck squamous cell carcinomas using patterns of gene expression. Cancer Cell 5: 489-500

Colantuoni C, Henry G, Zeger S, Pevsner J (2002) SNOMAD (Standardization and NOrmalization of MicroArray Data): web-accessible gene expression data analysis. Bioinformatics 18: $1540-1541$

Couldwell WT, Yong VW, Dore-Duffy P, Freedman MS, Antel JP (1992) Production of soluble autocrine inhibitory factors by human glioma cell lines. J Neurol Sci 110: 178-185

Dai H, van't Veer L, Lamb J, He YD, Mao M, Fine BM, Bernards R, van de Vijver M, Deutsch P, Sachs A, Stoughton R, Friend S (2005) A cell proliferation signature is a marker of extremely poor outcome in a subpopulation of breast cancer patients. Cancer Res 65: 4059-4066

Endl E, Gerdes J (2000) The Ki-67 protein: fascinating forms and an unknown function. Exp Cell Res 257: $231-237$

Garrity MM, Burgart LJ, Mahoney MR, Windschitl HE, Salim M, Wiesenfeld M, Krook JE, Michalak JC, Goldberg RM, O’Connell MJ, Furth AF, Sargent DJ, Murphy LM, Hill E, Riehle DL, Meyers CH, TE W (2004) Prognostic value of proliferation, apoptosis, defective DNA mismatch repair, and p53 overexpression in patients with resected Dukes' B2 or C colon cancer: a North Central Cancer Treatment Group Study. J Clin Oncol 22: $1572-1582$

Glinsky GV, Berezovska O, Glinskii AB (2005) Microarray analysis identifies a death-from-cancer signature predicting therapy failure in patients with multiple types of cancer. J Clin Invest 115: 1503-1521
Hilska M, Collan YU, O Laine VJ, Kossi J, Hirsimaki P, Laato M, Roberts PJ (2005) The significance of tumor markers for proliferation and apoptosis in predicting survival in colorectal cancer. Dis Colon Rectum 48: 2197-2208

Hippo Y, Taniguchi H, Tsutsumi S, Machida N, Chong J-M, Fukayama M, Kodama T, Aburatani H (2002) Global gene expression analysis of gastric cancer by oligonucleotide microarrays. Cancer Res 62: 233-240

Ihaka R, Gentleman R (1996) a language for data analysis and graphics. J Comput Graph Stat 5: 299-314

Inamura K, Fujiwara T, Hoshida $\mathrm{Y}$, Isagawa $\mathrm{T}$, Jones $\mathrm{MH}$, Virtanen $\mathrm{C}$ Shimane M, Satoh Y, Okumura S, Nakagawa K, Tsuchiya E, Ishikawa S, Aburatani H, Nomura H, Ishikawa Y (2005) Two subclasses of lung squamous cell carcinoma with different gene expression profiles and prognosis identified by hierarchical clustering and non-negative matrix factorization. Oncogene 24: 7105-7113

Kirschner-Schwabe R, Lottaz C, Todling J, Rhein P, Karawajew L, Eckert C, von Stackelberg A, Ungethum U, Kostka D, Kulozik AE, Ludwig W-D, Henze G, Spang R, Hagemeier C, Seeger K (2006) Expression of late cell cycle genes and an increased proliferative capacity characterize very early relapse of childhood acute lymphoblastic leukemia. Clin Cancer Res 12: $4553-4561$

Kosinski C, Li VSW, Chan ASY, Zhang J, Ho C, Tsui WY, Chan TL, Mifflin RC, Powell DW, Yuen ST, Leung SY, Chen X (2007) Gene expression patterns of human colon tops and basal crypts and BMP antagonists as intestinal stem cell niche factors. Proc Natl Acad Sci USA 104: $15418-15423$

Krasnoselsky AL, Whiteford CC, Wei JS, Bilke S, Westermann F, Chen Q-R, Khan J (2004) Altered expression of cell cycle genes distinguishes aggressive neuroblastoma. Oncogene 24: 1533-1541

Kuhn H, Braunlich J, Hammerschmidt S, Wirtz H (2004) Candidate genes upregulated in density dependent growth inhibition of lung cancer cells. Int J Oncol 25: 1481 - 1487

LaTulippe E, Satagopan J, Smith A, Scher H, Scardino P, Reuter V, Gerald WL (2002) Comprehensive gene expression analysis of prostate cancer reveals distinct transcriptional programs associated with metastatic disease. Cancer Res 62: 4499-4506

Livak KJ, Schmittgen TD (2001) Analysis of relative gene expression data using real-time quantitative PCR and the 2-[Delta][Delta]CT method. Methods 25: $402-408$ 
Motti ML, Califano D, Baldassarre G, Celetti A, Merolla F, Forzati F, Napolitano M, Tavernise B, Fusco A, Viglietto G (2005) Reduced E-cadherin expression contributes to the loss of p27kip1-mediated mechanism of contact inhibition in thyroid anaplastic carcinomas. Carcinogenesis 26: $1021-1034$

Paik S, Shak S, Tang G, Kim C, Baker J, Cronin M, Baehner FL, Walker MG, Watson D, Park T, Hiller W, Fisher ER, Wickerham DL, Bryant J, Wolmark N (2004) A multigene assay to predict recurrence of tamoxifen-treated, node-negative breast cancer. $N$ Engl J Med 351: $2817-2826$

Pawitan Y, Bjohle J, Amler L, Borg AL, Egyhazi S, Hall P, Han X, Holmberg L, Huang F, Klaar S, Liu ET, Miller L, Nordgren H, Ploner A, Sandelin K, Shaw PM, Smeds J, Skoog L, Wedren S, Bergh J (2005) Gene expression profiling spares early breast cancer patients from adjuvant therapy: derived and validated in two population-based cohorts. Breast Cancer Res 7: R953-R964

Perou CM, Jeffrey SS, van de Rijn M, Rees CA, Eisen MB, Ross DT, Pergamenschikov A, Williams CF, Zhu SX, Lee JCF, Lashkari D, Shalon D, Brown PO, Botstein D (1999) Distinctive gene expression patterns in human mammary epithelial cells and breast cancers. Proc Natl Acad Sci USA 96: $9212-9217$

Perou CM, Sorlie T, Eisen MB, van de Rijn M, Jeffrey SS, Rees CA, Pollack JR, Ross DT, Johnsen H, Akslen LA, Fluge O, Pergamenschikov A, Williams C, Zhu SX, Lonning PE, Borresen-Dale A-L, Brown PO, Botstein D (2000) Molecular portraits of human breast tumours. Nature 406: 747-752

Rosenwald A, Wright G, Wiestner A, Chan WC, Connors JM, Campo E, Gascoyne RD, Grogan TM, Muller-Hermelink HK, Smeland EB (2003) The proliferation gene expression signature is a quantitative integrator of oncogenic events that predicts survival in mantle cell lymphoma. Cancer Cell 3: $185-197$

Saeed AI, Sharov V, White J (2003) TM4: a free, open-source system for microarray data management and analysis. Biotechniques 34: 374-378

Sorlie T, Perou CM, Tibshirani R, Aas T, Geisler S, Johnsen H, Hastie T, Eisen MB, van de Rijn M, Jeffrey SS, Thorsen T, Quist H, Matese JC, Brown PO, Botstein D, Lonning PE, Borresen-Dale A-L (2001) Gene expression patterns of breast carcinomas distinguish tumor subclasses with clinical implications. Proc Natl Acad Sci USA 98: 10869-10874

Steinman RA, Wentzel A, Lu Y, Stehle C, JR G (2003) Activation of Stat3 by cell confluence reveals negative regulation of Stat 3 by cdk2. Oncogene 22: $3608-3615$

Tusher VG, Tibshirani R, Chu G (2001) Significance analysis of microarrays applied to the ionizing radiation response. Proc Natl Acad Sci USA 98: $5116-5121$

van de Vijver MJ, He YD, van 't Veer LJ, Dai H, Hart AAM, Voskuil DW, Schreiber GJ, Peterse JL, Roberts C, Marton MJ, Parrish M, Atsma D, Witteveen A, Glas A, Delahaye L, van der Velde T, Bartelink H, Rodenhuis S, Rutgers ET, Friend SH, Bernards R (2002) A geneexpression signature as a predictor of survival in breast cancer. $N$ Engl $J$ Med 347: 1999-2009

Welsh JB, Zarrinkar PP, Sapinoso LM, Kern SG, Behling CA, Monk BJ, Lockhart DJ, Burger RA, Hampton GM (2001) Analysis of gene expression profiles in normal and neoplastic ovarian tissue samples identifies candidate molecular markers of epithelial ovarian cancer. Proc Natl Acad Sci USA 98: 1176-1181

Whitfield ML, George LK, Grant GD, Perou CM (2006) Common markers of proliferation. Nat Rev Cancer 6: 99-106 